\title{
INHIBITION: A CAUTIONARY TALE
}

\author{
John W. Donahoe and David G. Palmer \\ UNIVERSITY OF MASSACHUSETTS-AMHERST AND \\ MOUNT HOLYOKE COLLEGE
}

Some years ago, the first author introduced B. F. Skinner to an audience of graduate students with the following words: "Professor Skinner is probably best known to you for asking a question that you have likely asked yourselves, although I suspect that his reasons for asking the question were somewhat different from yours. The question is: Are theories of learning necessary?" Skinner acknowledged the introduction by saying, "While the students' reasons may be different from mine, our answers are the same."

The question "Are theories of learning necessary?" referred, of course, to the title of the paper in which Skinner rejected theories of a particular type, namely, those known as intervening-variable theories (Skinner, 1950). Such theories, most notably those promulgated by Hull and Spence, were said to be not only unnecessary but also harmful, in that they diverted attention from a genuine experimental analysis of behavior. In this, Skinner was echoing Huxley's comment that certain contemporary alternatives to Darwin's account of evolution through natural selection "worked ... not only negative, but positive ill, by discouraging inquiry" (Huxley, 1908, cited in Ellegard, 1958, p. 182).

The view of theory propounded in "Are theories of learning necessary?" was largely a restatement of the position described 12 years earlier in The Behavior of Organisms (Skinner, 1938), now buttressed by experimental findings that illustrated several of the major points. Many of these points may, in turn, be traced to still earlier writings (e.g., Skinner, 1935).

This review examines Skinner's program

Preparation of this article was supported by Grant 8409948 from the National Science Foundation, Behavioral and Neural Sciences. Requests for reprints should be sent to J. W. Donahoe, Department of Psychology, University of Massachusetts at Amherst, Tobin Hall, Amherst, Massachusetts 01003. for the experimental analysis of behavior using as a vehicle the concept of "inhibition" treated in The Behavior of Organisms. Skinner's reservations concerning inhibition are presented, followed by a brief summary of the changing status of the concept within behavior analysis. The conclusion is reached that Skinner's early misgivings were well conceived, and that the failure consistently to heed them has worked mischief.

In The Behavior of Organisms, Skinner rejected the concept of inhibition as it was conventionally described: "The property of the mere direction of the change does not establish a useful class of data. The various changes included in the class may easily be distinguished on the basis of the operations that produce them, and there is little to be gained by giving them a common name" ( $p$. 17). The only use of the concept to which he grudgingly acceded was defended on historical, not scientific, grounds: "One kind of negative change in strength has some historical right to the term inhibition. The operation is the presentation of a stimulus which does not itself affect the response in question.... It is the only one which will be used here" (p. 17). In point of fact, however, this use of the term failed to resurface in the remainder of the book.

\section{THE NEED FOR THE DIRECT MEASUREMENT OF INHIBITION}

What were the evils potentially worked by the concept of inhibition? Several were identified by Skinner. First, he took exception to the use of inhibition in theories of what he called the "Conceptual Nervous System" (p. 422). At the time of its writing, this objection referred most directly to Pavlov's use of inhibition in accounts of purely behavioral data (Pavlov, 1927), but it later applied with equal force to some of Hull's (1943) theo- 
rizing. Because inhibition occupied a generally accepted and respected place in physiological theorizing, many behavioral scientists felt comfortable incorporating the term into their technical vocabularies. This uncritical acceptance was a kind of converse McCarthyism in which inhibition was found innocent because of its association with another-and presumably better established-scientific discipline. Innocence by association meets no formal criterion of scientific thinking, of course. Nevertheless, this argument frequently makes its appearance in justifications of the role of inhibition in behavioral theorizing (see Hearst, 1972, pp. 18-19), particularly among those familiar with physiology. This audience often interprets a reluctance to welcome inhibition into the technical vocabulary as a confirmation of the mistaken view that behavior analysts are hostile to efforts to coordinate physiological and behavioral observations or that behavior analysts have a slavish commitment to an outmoded philosophy of science-operationalism. (For the radical behavioral perspective on operationalism, see Skinner, 1945.)

Skinner objected to the quasi-physiological flavor of inhibition on at least two grounds. Most widely recognized, Skinner wished to establish the study of behavior as a science that was as independent of physiology as were any two other sciences bearing similar relations to one another (e.g., the sciences of physiology and chemistry). Regarding behavior and physiology (Skinner referred to the latter as "neurology"), "The very notion of a 'neurological correlate' implies what I am here contending - that they are two independent subject matters. ... I am asserting, then, not only that a science of behavior is independent of neurology but that it must be established as a separate discipline whether or not a rapprochement with neurology is ever attempted" (pp. 423-424). Indeed, Skinner believed that an adequate behavioral analysis was a prerequisite for any rapprochement. "What is generally not understood by those interested in establishing neurological bases is that a rigorous description at the level of behavior is necessary for the demonstration of a neurological correlate" (p. 422). Skinner was not opposed to efforts to establish neural correlates of behavior; he regarded differences in belief concerning the fruitfulness of such undertakings as "a matter of tastes" (p. 426).
"I am not overlooking the advance that is made in the unification of knowledge when terms at one level of analysis are defined ("explained") at a lower level" (p. 428).

What is less widely recognized is that Skinner also objected to the use of inhibition within the "neurology" of the day. "But a Conceptual Nervous System is probably not what the neurologist has in mind when he speaks of the neural correlates of behavior. The correlation demanded as an explanation is with a science of neurology which completes its local references and devises techniques for the direct [sic] observation of synaptic and other processes" (p. 422). Skinner then went on to cite with approval the views of a contemporary physiologist to similar effect:

\begin{abstract}
It may be that inhibition opposes excitation by affecting the permeability or other properties of the synapse and preventing impulses from reaching the moto-neurone; or it may be that it acts by arousing in the cell body processes which oppose those of excitation. It seems to me that no data at hand suffice to determine this question, and further, that its solution is not essential to a consideration of the dynamic properties of reflex inhibition." (Forbes, 1912, quoted on pp. 422-423 of Skinner, 1938)
\end{abstract}

Thus, Skinner regarded inhibition as an appeal to fantasy physiology even within the "neurology" of the time.

Because it will prove useful in the present paper, a brief digression is warranted to consider the treatment of inhibition within modern neurophysiology (Eccles, 1957). Neurons normally have a resting potential across the cell membrane. When this resting potential falls sufficiently, neurochemical events are initiated that cause an action potential to be propagated along the neuron and, eventually, to release a neurotransmitter that diffuses across the synapse and stimulates subsequent neurons in the pathway. Changes in the resting potential of the first neuron are themselves produced by neurotransmitters released by earlier neurons in the pathway. Some neurotransmitters lower the resting potential of the neuron and, because this change makes an action potential more likely, they are called excitatory neurotransmitters. Other neurotransmitters raise the resting potential of the neuron and, because this change makes an 
action potential less likely, they are called inhibitory neurotransmitters.

Just as Skinner had forecast, the modern account of neural inhibition appeals to "the direct observation of synaptic and other processes" and does not infer inhibition (or excitation) from the output of the neuron. To be specific, inhibition is not inferred from a decreased frequency of action potentials. A decreased frequency could be produced by either a decrease in an excitatory neurotransmitter or an increase in an inhibitory neurotransmitter. Instead, inhibition is reserved for those instances in which a neurotransmitter produces an observed increase in the resting potential of the neuron. The effect of the increase in potential is to decrease the frequency of action potentials in that neuron below what it would otherwise be. The crucial point is that the output of the system (the frequency of action potentials) does not provide a sufficient basis for inferences about the status of inhibition. Only direct observations of the antecedent processes of which the output is a function permit valid statements about inhibition.

\section{THE NEED FOR THE \\ INDEPENDENT MEASUREMENT OF INHIBITION}

For Skinner, the direct measurement of inhibitory processes accomplished a second goal; it removed the need to infer the status of inhibition from measures whose values were influenced by behavioral processes in addition to the putative inhibitory process. If inhibitory processes were not measured directly, then the experimenter was forced to infer the status of inhibition from its presumed decremental effect on the strength of responses conditioned to other stimuli. The validity of this inference depended upon holding constant all other variables that might affect responding during the other stimuli. Without direct measurement of the inhibitory behavioral processes, there could be no assurance that the measured response was independent of the effects of these other variables.

Instead of making the assumption that all variables except those affecting inhibitory processes were held constant (an assumption whose validity would forever remain uncertain in the absence of direct measurement of the putative inhibitory processes), Skinner offered alternative accounts of phenomena for which others appealed to inhibition. Among these phenomena were extinction, spontaneous recovery, and disinhibition (pp. $96 \mathrm{ff}$ ); inhibition of delay and trace conditioning (pp. $268 \mathrm{ff}$ ); and conditioned inhibition and discrimination of a stimulus (pp. $232 \mathrm{ff}$ ).

To give some sense of the alternative approach taken by Skinner, consider conditioned inhibition. To demonstrate conditioned inhibition, Pavlov had exposed a dog to a differential conditioning procedure in which $\mathrm{S}^{\mathrm{A}}$ (e.g., a tone) was paired with food, but when $\mathrm{S}^{\mathrm{A}}$ appeared in simultaneous compound with $S^{B}$ (e.g., a light) food was withheld. Subsequently, $\mathrm{S}^{\mathrm{B}}$ was said to be a conditioned inhibitor if salivation were decreased when $\mathrm{S}^{\mathrm{B}}$ was compounded with still a third stimulus, $\mathrm{S}^{\mathrm{C}}$ (e.g., a tactile stimulus), known to evoke salivation through its prior pairing with food. Instead of endowing $S^{B}$ with inhibitory properties, Skinner regarded the procedure as a specific instance of differential conditioning, and "a discrimination is only a modified form of extinction, and no concept of inhibition is needed to account for it. $\mathrm{S}^{\mathrm{B}}$ does not act to inhibit the reflex of $\mathrm{S}^{\mathrm{A}} \ldots$ It is the differentiating property of a composite stimulus" (p. 232). He then suggested that the decrement in responding observed during $\mathrm{S}^{\mathrm{C}}$ might also be the result of the generalization of extinction between $S^{B}$ and $S^{C}$ or between the stimulus compounds $\mathrm{S}^{\mathrm{AB}}$ and $\mathrm{S}^{\mathrm{CB}}$.

In the absence of a direct measure of the inhibitory behavioral process, Skinner said of the attempt to view response frequency as a function of the difference between the inferred strengths of inhibition and excitation: "[In the pair of terms] inhibition-excitation ... inhibition refers to any low state of strength. ... We do not need the term because we do not need its opposite. Excitation and inhibition refer to what is here seen to be a continuum of degrees of reflex strength, and we have no need to designate its two extremes. ... There is an obvious danger in paired concepts of this sort, for they place a system under the suspicion of being designed to catch a datum no matter where it falls" (pp. 1718).

Given the possibility of alternative accounts that did not rely upon problematic inferences, Skinner favored a more parsimonious inter- 
pretation in which changes in responding reflected changes in the strength of one reflex. "The principal argument against the notion of a suppressing force in extinction is logical. The number of terms needed in the system is unnecessarily increased. The interpretation of an observed state of inactivity employs the double postulate of excitatory and inhibitory forces which cancel each other" (p. 97). If the excitation-inhibition account of extinction were accepted, Skinner held that consistency would then demand that "reconditioning must be regarded as the removal of inhibition, although it has all the external properties of original conditioning. This can hardly be justified by designating original conditioning also as a removal of inhibition, since we should be led to the absurd conclusion that all possible conditioned reflexes pre-exist in the organism in a state of suppressed excitability" (p. 97).

\section{BEHAVIOR-ANALYTIC RESEARCH ON INHIBITION}

Skinner's exposure of the conceptual complexities of inhibition in behavioral research, in concert with his alternative proposals for interpreting the very phenomena that inhibition was intended to explain, had the effect of discouraging behavior-analytic research on these issues. Note that such an effect is not a necessary consequence of Skinner's analysis. On the contrary, the analysis had identified two potentially promising lines of inquiry for the study of those circumstances in which inhibitory processes were invoked: (a) efforts could be made to measure directly the inhibitory behavioral processes occurring in such circumstances and (b) efforts could be made to evaluate the cogency of Skinner's alternative interpretations of the purportedly inhibitory phenomena.

In this section, we trace the major conceptual and methodological changes that occurred within the experimental literature in pursuit of the will-o'-the-wisp of inhibition. We do not pretend to a comprehensive review of that body of research or to a critical evaluation of even those few studies that are cited, except insofar as they bear on general issues in the analysis of inhibition that were identified in The Behavior of Organisms.

Almost 25 years elapsed before the rebirth (disinterment?) of inhibition in behavior-analytic research. Using a variant of a procedure developed by Norman Guttman and his students (Guttman \& Kalish, 1956), stimulusgeneralization gradients were obtained that provided a measure of stimulus control by the stimulus $(\mathrm{S}-)$ previously correlated with extinction (Honig, Boneau, Burstein, \& Pennypacker, 1963; Jenkins \& Harrison, 1962). The procedural variant permitted the gradient to reflect control by $\mathrm{S}-$ under conditions in which the assumption that other variables were held constant could be made more convincingly.

As an example of the new procedure, $\mathrm{S}-$ might consist of a vertical white line on a colored background whereas the stimulus correlated with the reinforcer $(\mathrm{S}+)$ was the color alone. A generalization gradient along the line-orientation dimension could then be obtained by measuring the frequency of responding while varying the line orientation of test stimuli with the background color held constant at the $\mathrm{S}+$ value. Because variations in line orientation could occur independently of color (i.e., without concomitant variation in the proximity of the test stimuli to $S+$ ), changes in response frequency could be attributed to variations in line orientation alone. For this reason, differential training procedures employing such stimuli are called orthogonal procedures. The use of the $\mathrm{S}+$ color as the context in which control by $\mathrm{S}-$ was assessed also appeared to solve another problem. The use of the $\mathrm{S}+$ context elevated the general level of responding sufficiently for control by $\mathrm{S}-$, which decreased the measured response, to be demonstrated by U-shaped gradients of the response controlled by $\mathrm{S}+$. By means of this procedure, investigators were able to obtain gradients that had minima in the vicinity of $\mathrm{S}-$ and then progressively increased as the test stimuli departed from $\mathrm{S}$-.

For present purposes, the critical aspect of the orthogonal procedure is that it permitted an independent measure of the putative inhibitory processes, but one that remained indirect. That is, there was no way to distinguish between two equal rates of responding that had different antecedents. Because only the response controlled by $\mathrm{S}+$ was measured, a given value of the dependent variable could arise because of responding controlled by $\mathrm{S}+$ 
alone or because of the interrelation between responses controlled by $\mathrm{S}+$ and generalized "inhibitory" responses controlled by $\mathrm{S}-$. The interrelation between responses of these two origins could be potentially complex if the occurrence of one could influence the occurrence of the other (i.e., if there were interactions between the two responses). Without direct measures of the inhibitory behavioral processes controlled by $\mathrm{S}-$, the interrelations and possible interactions between responses controlled by $\mathrm{S}+$ and those controlled by $\mathrm{S}-$ could not be examined. Thus, although observations obtained with the orthogonal procedure more closely met Skinner's criterion of providing measures that were independent of variations in $\mathrm{S}+$, they continued to provide only an indirect reflection of any inhibitory behavioral processes.

A second major influence on the direction of research on inhibitory processes was the finding that, using the conditioned-inhibition procedure, $S^{B}$ could decrease responding when presented in compound with $\mathrm{S}^{\mathrm{C}}$ under conditions in which the processes identified in Skinner's alternative interpretation of the phenomenon were not wholly responsible for the effect (Brown \& Jenkins, 1967). Although these experiments demonstrated that a failure to discriminate between $S^{B}$ and $S^{C}$ or between the stimulus compounds $S^{\mathrm{AB}}$ and $\mathrm{S}^{\mathrm{CB}}$ was not necessary for the effect, they did not identify the behavioral processes that were involved. No direct measures of inhibitory behavioral processes were provided, and Skinner's analysis of conditioned inhibition as a discrimination with $\mathrm{S}^{\mathrm{B}}$ as "the differentiating property of a composite stimulus" remained experimentally unchallenged (cf. Hearst, 1972, p. 25).

The availability of an improved method for indirectly measuring inhibitory processes, together with the demonstration of conditioned inhibition under circumstances in which Skinner's alternative interpretations were insufficient, was generally taken as a sanction for the study of inhibition (e.g., Hearst, Besley, \& Farthing, 1970; Jenkins, 1965). Note, however, that the original limitations imposed upon an experimental analysis by the indirect measurement of inhibitory processes remained. Note also that the refutation of conditioned inhibition as wholly due to a failure to discriminate is not equivalent to an af- firmation of inhibitory processes as the origin of the phenomenon.

In addition to the new experimental procedures, certain theoretical developments arising from outside the behavior-analytic tradition influenced research. In particular, inhibition played an important role in contemporaneous intervening-variable theories of respondent conditioning (e.g., Rescorla, 1969). Because inhibitory processes were not directly measured in this work either, their presence in respondent conditioning also remained an inference from other measures. Two tests were proposed as talismans by which inhibitory processes were inferred. First, an inhibitory stimulus must decrease responding when presented with another stimulus that would otherwise evoke responding. This is the familiar conditioned-inhibition procedure, but it now became known as the summation test of inhibition. Second, if the putative inhibitor were subsequently paired with a reinforcer, the acquisition of responding must be retarded relative to an appropriate control condition. This procedure constituted the retardation test, and a stimulus was required to meet both the summation and retardation tests before the inference was accepted that the stimulus controlled inhibitory processes.

We have seen already that the summation test (conditioned inhibition) provides only indirect and inconclusive evidence that a stimulus controls inhibitory behavioral processes. The retardation test suffers these and other difficulties, especially in operant, as distinct from respondent, procedures. Consider the case in which a response is reinforced intermittently in the presence of a putative inhibitory stimulus (cf. Hearst et al., 1970). If the inhibitory stimulus does control specific behavior, the occurrence of which does not preclude the occurrence of reinforcers, then this inhibitory behavior may actually be strengthened by the reinforcers occurring during the retardation test. That is, inhibitory behavior may be adventitiously reinforced and thereby persist indefinitely (cf. Skinner, 1948). Under such circumstances, "inhibition" will not be reduced but will be maintained, and may compete with the "inhibited" response. Without a direct measure of the inhibitory behavioral processes, it is difficult to distinguish between very different accounts of the events occurring during a retardation test. 
Although there were occasional efforts to measure inhibitory behavioral processes directly (e.g., Catania, 1969; Jenkins, 1965; Terrace, 1972) and occasional expressions of the desirability of having such measures (e.g., Hearst, 1972; Hearst et al., 1970), much of the research was devoted to applying the new orthogonal discrimination procedures to problems defined by intervening-variable theories. As the major example, efforts were made to use generalization gradients determined on the $\mathrm{S}-$ and $\mathrm{S}+$ dimensions after orthogonal discrimination training to evaluate Spence's (1936) analysis of discrimination formation. For Spence, discrimination was viewed as the product of interacting gradients of excitation and inhibition (e.g., Hanson, 1959; Hearst, 1969; Marsh, 1972). As sometime participants in this enterprise (e.g., Donahoe \& Lumia, 1971), ${ }^{1}$ we must reluctantly conclude that much of such work has minimal enduring value.

To be sure, the renewed enthusiasm for inhibition in the experimental literature did not produce a return to the very broad use of the term that marked earlier work. In later research, the term was reserved for the operant analog of conditioned inhibition. For example, Hearst et al. (1970) defined an inhibitory stimulus as "a stimulus that develops during conditioning the capacity to decrease response strength below the level occurring when that stimulus is absent" (p. 376). However, it was common to contrast inhibition with excitation-a concept, it will be recalled, that Skinner had found equally unhelpful (e.g., Brown \& Jenkins, 1967; Hearst et al., 1970).

Can there be any objection to the term inhibition if it is confined to a stimulus function that is symmetrical and directly opposed to the ("excitatory") discriminative-stimulus function? Indeed there can be, for the term reifies a behavioral process for which generalization testing after orthogonal discrimination training provided no direct evidence. Consider the conditioned-suppression procedure of Estes and Skinner (1941). In this procedure a "neutral" stimulus is paired with a strong aversive stimulus and presumably

${ }^{1}$ Donahoe, J. W., \& Lumia, A. R. (1971). Contextual effects on excitatory and inhibitory gradients. Paper presented at the meetings of the Psychonomic Society, St. Louis, MO. becomes a conditioned elicitor of a constellation of responses. When this stimulus is later presented to the organism while it is engaging in some measurable activity, a strong "inhibitory" effect is observed. That is, ongoing operant behavior declines markedly in rate. Thus, if a rat is shocked in the presence of a tone, the tone will subsequently disrupt an otherwise steady rate of bar pressing, presumably because responses elicited by the tone (e.g., freezing) are incompatible with bar pressing. Although the tone appears to pass the operational test of a conditioned inhibitor, the conditioned-suppression test is widely used today to assess the "excitatory" strength of the suppressing stimulus! Clearly, a stimulus can serve to reduce the rate of a response without invoking a new stimulus function (i.e., inhibition).

One might argue that the conditionedsuppression procedure is easily distinguished from the conditioned-inhibition procedure and that the term inhibition should be reserved for circumstances in which response competition cannot be invoked. But it is no easy matter to rule out competition. First, extinction is aversive and often occasions "emotional" behavior. In a conditioned-inhibition procedure, it is plausible to assume that the putative inhibitor constitutes the occasion on which such behavior occurs (e.g., Terrace, 1966). Moreover, this type of interpretation of inhibitory processes is not confined to behavior of "emotional" origin. In general, the activity of an organism in a conditioned-inhibition procedure may be characterized as follows: In the presence of $\mathrm{S}+$, the organism engages in one set of responses; in the presence of $\mathrm{S}-$, it engages in a second set of responses (cf. Staddon, 1977). It is unnecessary to invoke opposing excitatory and inhibitory behavioral processes to account for a change in the rate of whichever of these responses one happens to be measuring.

\section{GURRENT STATUS OF INHIBITION}

In the 8-year period from 1968 through 1975 , the regained respectability of inhibition was shown by the publication in $J E A B$ of 61 papers assigned the key word "inhibition." In the subsequent 8-year period from 1976 through 1983, only 13 papers bearing that key word have appeared. What is responsible 
for the almost $80 \%$ reduction in the number of papers on inhibition? The dwindling number of papers concerned with inhibition cannot be due to the disappearance of or lack of interest in the phenomena that the concept was intended to explain-phenomena endure, and phenomena of such general significance as stimulus discrimination are hardly of passing interest. To understand the reinterment of inhibition following its failed resurrection, it is useful to repeat Skinner's view in The Behavior of Organisms that the concept of inhibition was either not required because other processes provided a potentially adequate account or, if it was to be useful, inhibitory behavioral processes must be measured directly. Subsequent analysis has sustained both of these claims.

Regarding the lack of necessity of a separate inhibitory process, research has shown that conditioned inhibition - the quintessential inhibitory phenomenon-may be treated as a special case of the discrimination of a stimulus. In the words of those responsible for the modern analysis, "The theory appeals to no special inhibitory process.... To speak of inhibition in the context of this model is simply to speak of a range of values along the associative-strength continuum" (Wagner \& Rescorla, 1972, p. 307). Thus, Skinner's general view that $S^{\mathrm{B}}$ in the conditioned inhibition paradigm "is the differentiating property of a composite stimulus" has been vindicated. It should be noted, however, that the specific proposal for accounting for conditioned inhibition (and a wide range of other phenomena as well) did not arise from Skinner's thinking. Instead, the modern account arose from a concern with the nature of the reinforcement process itself (Kamin, 1968, 1969; Rescorla \& Wagner, 1972). Skinner, like Darwin before him, has chosen to devote his energies to exploring the implications of selection and not to identifying its mechanisms, but that is another story. More work is required before the analysis of reinforcement is placed on a firm behavioral footing, and such efforts are underway (e.g., Donahoe, Crowley, Millard, \& Stickney, 1982; Donegan \& Wagner, 1987).

Regarding the direct measurement of inhibitory behavioral processes, great progress has been achieved through the observation and analysis of the times between successive occurrences of the response upon which rein- forcers are dependent. These interresponse times provide a means for assessing the other responses in which the organism is engaged in addition to the response selected by the reinforcer. Like all behavior, these other responses require time for their occurrence and, therefore, the duration of the interresponse time provides a common scale on which to measure it. The frequency distribution of the durations of these interresponse times provides a measure that is comparable to an ethogram-an exhaustive categorization of the responses within the organism's repertoire (see Palmer, Donahoe, \& Crowley, 1985). Through the use of the interresponse-time distribution, a wide range of discriminative and generalization phenomena that were discussed previously in terms of excitatory and inhibitory processes may now be analyzed as the interplay among a variety of specific responses controlled by the various stimuli in the test environment (e.g., Crowley, 1979; Gray, 1976; Migler, 1964; Staddon, 1977; for reviews, see Bickel \& Etzel, 1985; Donahoe \& Wessells, 1980, pp. 176-196).

Finally, what of the historical use of inhibition to refer to a "negative change in strength ... [due to] ... the presentation of a stimulus which does not itself affect the response in question." In this use of the term, inhibition is invoked to explain a decrement in the measured response when no other competing or interfering behavioral processes have been identified. It is a term that signifies one of two states: either our ignorance of the relevant behavioral processes or the absence of such processes. In short, the term denotes no process that can assume any explanatory role whatsoever at the behavioral level of analysis. Moreover, because there is no phenomenal distinction between processes of which we are ignorant and those which are truly absent, the very existence of the term blinds us to the distinction and thereby contents us with our ignorance.

We may conclude, then, that "inhibition" appears with declining frequency in the behavior-analytic literature because it simply serves no function, either scientifically or heuristically. All of the phenomena whose understanding inhibition was intended to aid are now analyzed in terms of behavioral processes, none of which describes a new stimulus function, which is the implication of the term 
"inhibition." Skinner said as much 50 years ago in The Behavior of Organisms, and we suspect that several other concepts appearing in the current literature await a similar fate when they are subjected to a thoroughgoing experimental analysis-but that, too, is another story.

\section{REFERENCES}

Bickel, W. K., \& Etzel, B. C. (1985). The quantal nature of controlling stimulus-response relations as measured in tests of stimulus generalization. Journal of the Experimental Analysis of Behavior, 44, 245-270.

Brown, P. L., \& Jenkins, H. M. (1967). Conditioned inhibition and excitation in operant discrimination learning. Journal of Experimental Psychology, 75, 255266.

Catania, A. C. (1969). Concurrent performances: Inhibition of one response by reinforcement of another. Journal of the Experimental Analysis of Behavior, 12, 731-744.

Crowley, M. A. (1979). The allocation of time to temporally defined behaviors: Responding during stimulus generalization. Journal of the Experimental Analysis of Behavior, 32, 191-197.

Donahoe, J. W., Crowley, M. A., Millard, W. J., \& Stickney, K. A. (1982). A unified principle of reinforcement: Some implications for matching. In $\mathbf{M}$. L. Commons, R. J. Herrnstein, \& H. Rachlin (Eds.), Quantitative analyses of behavior: Vol. 2. Matching and maximizing accounts (pp. 493-521). Cambridge, MA: Ballinger.

Donahoe, J. W., \& Wessells, M. G. (1980). Learning, language, and memory. New York: Harper \& Row.

Donegan, N. H., \& Wagner, A. R. (1987). Conditioned diminution and facilitation of the UR. In I. Gormezano, W. F. Prokasy, \& R. F. Thompson (Eds.), Classical conditioning III: Behavioral, neurophysiological, and neurochemical studies in the rabbit (pp. 339-369). Hillsdale, NJ: Erlbaum.

Eccles, J. C. (1957). The physiology of nerve cells. Baltimore, MD: Johns Hopkins Press.

Ellegard, A. (1958). Darwin and the general reader. Göteborg, Sweden: Göteborgs Universitets Arsskrift.

Estes, W. K., \& Skinner, B. F. (1941). Some quantitative properties of anxiety. Journal of Experimental Psychology, 29, 390-400.

Gray, V. A. (1976). Stimulus control of differentialreinforcement-of-low-rate responding. Journal of the Experimental Analysis of Behavior, 25, 199-207.

Guttman, N., \& Kalish, H. I. (1956). Discriminability and stimulus generalization. Journal of Experimental Psychology, 51, 79-88.

Hanson, H. M. (1959). Effects of discrimination training on stimulus generalization. Journal of Experimental Psychology, 58, 321-334.

Hearst, E. (1969). Excitation, inhibition, and discrimination learning. In N. J. Mackintosh \& W. K. Honig (Eds.), Fundamental issues in associative learning (pp. 1-41). Halifax: University of Dalhousie Press.

Hearst, E. (1972). Some persistent problems in the analysis of conditioned inhibition. In R. A. Boakes \& M. S. Halliday (Eds.), Inhibition and learning (pp. 5-39). London: Academic Press.

Hearst, E., Besley, S., \& Farthing, G. W. (1970). Inhibition and the stimulus control of operant behavior. Journal of the Experimental Analysis of Behavior, 14, 373-409.

Honig, W. K., Boneau, C. A., Burstein, K. R., \& Pennypacker, H. S. (1963). Positive and negative generalization gradients obtained after equivalent training conditions. Journal of Comparative and Physiological Psychology, 56, 111-116.

Hull, C. L. (1943). Principles of behavior. New York: Appleton-Century-Crofts.

Jenkins, H. M. (1965). Generalization gradients and the concept of inhibition. In D. I. Mostofsky (Ed.), Stimulus generalization (pp. 55-61). Stanford, CA: Stanford University Press.

Jenkins, H. M., \& Harrison, R. H. (1962). Generalization gradients of inhibition following auditory discrimination learning. Journal of the Experimental Analysis of Behavior, 5, 435-441.

Kamin, L. J. (1968). "Attention-like" processes in classical conditioning. In M. R. Jones (Ed.), Miami symposium on the prediction of behavior (pp. 9-31). Coral Gables, FL: University of Miami Press.

Kamin, L. J. (1969). Predictability, surprise, attention, and conditioning. In B. A. Campbell \& R. M. Church (Eds.), Punishment and aversive behavior (pp. 279-296). New York: Appleton-Century-Crofts.

Marsh, G. (1972). Prediction of peak shift in pigeons from gradients of excitation and inhibition. Journal of Comparative and Physiological Psychology, 81, 262266.

Migler, B. (1964). Effects of averaging data during stimulus generalization. Journal of the Experimental Analysis of Behavior, 7, 303-307.

Palmer, D. C., Donahoe, J. W., \& Crowley, M. A. (1985). Discriminated interresponse times: Role of autoshaped responses. Journal of the Experimental Analysis of Behavior, 44, 301-313.

Pavlov, I. P. (1927). Conditioned reflexes (G. V. Anrep, Trans.). London: Oxford University Press.

Rescorla, R. A. (1969). Pavlovian conditioned inhibition. Psychological Bulletin, 72, 77-94.

Rescorla, R. A., \& Wagner, A. R. (1972). A theory of Pavlovian conditioning: Variations in the effectiveness of reinforcement and nonreinforcement. In A. H. Black \& W. F. Prokasy (Eds.), Classical conditioning II: Current research and theory (pp. 64-99). New York: Appleton-Century-Crofts.

Skinner, B. F. (1935). The generic nature of the concepts of stimulus and the response. Journal of General Psychology, 12, 40-65.

Skinner, B. F. (1938). The behavior of organisms. New York: Appleton-Century.

Skinner, B. F. (1945). The operational analysis of psychological terms. Psychological Review, 52, 270-277.

Skinner, B. F. (1948). "Superstition" in the pigeon. Journal of Experimental Psychology, 38, 168-172.

Skinner, B. F. (1950). Are theories of learning necessary? Psychological Review, 57, 193-216.

Spence, K. W. (1936). The nature of discrimination learning in animals. Psychological Review, 43, 427449.

Staddon, J. E. R. (1977). Behavioral competition in 
conditioning situations: Notes toward a theory of generalization and inhibition. In $\mathbf{H}$. Davis \& $\mathbf{H}$. $\mathbf{M}$. B. Hurwitz (Eds.), Operant-Pavlovian interactions (pp. 103-131). Hillsdale, NJ: Erlbaum.

Terrace, H. S. (1966). Stimulus control. In W. K. Honig (Ed.), Operant behavior: Areas of research and applilcation (pp. 271-344). New York: Appleton-Century-Crofts.
Terrace, H. S. (1972). Conditioned inhibition is successive discrimination learning. In $\mathbf{R}$. A. Boakes \& M. S. Halliday (Eds.), Inhibition and learning (pp. 99-119). London: Academic Press.

Wagner, A. R., \& Rescorla, R. A. (1972). Inhibition in Pavlovian conditioning: Application of a theory. In R. A. Boakes \& M. S. Halliday (Eds.), Inhibition and learning (pp. 301-336). London: Academic Press. 